\title{
DESCRIBING NEIGHBORHOODS OF 5-VERTICES IN 3-POLYTOPES WITH MINIMUM DEGREE 5 AND WITHOUT VERTICES OF DEGREES FROM 7 TO $11^{1}$
}

\author{
Oleg V. Borodin, Anna O. Ivanova \\ AND \\ Olesya N. KAZAK \\ Institute of Mathematics Siberian Branch \\ Russian Academy of Sciences \\ Novosibirsk, 630090, Russia \\ e-mail: brdnoleg@math.nsc.ru \\ shmgnanna@mail.ru \\ agazandjelos@gmail.com
}

\begin{abstract}
In 1940, Lebesgue proved that every 3-polytope contains a 5-vertex for which the set of degrees of its neighbors is majorized by one of the following sequences:

$(6,6,7,7,7),(6,6,6,7,9),(6,6,6,6,11)$,

$(5,6,7,7,8),(5,6,6,7,12),(5,6,6,8,10),(5,6,6,6,17)$,

$(5,5,7,7,13),(5,5,7,8,10),(5,5,6,7,27)$,

$(5,5,6,6, \infty),(5,5,6,8,15),(5,5,6,9,11)$,

$(5,5,5,7,41),(5,5,5,8,23),(5,5,5,9,17)$,

$(5,5,5,10,14),(5,5,5,11,13)$.

In this paper we prove that every 3 -polytope without vertices of degree from 7 to 11 contains a 5-vertex for which the set of degrees of its neighbors is majorized by one of the following sequences: $(5,5,6,6, \infty),(5,6,6,6,15)$, $(6,6,6,6,6)$, where all parameters are tight.
\end{abstract}

Keywords: planar graph, structure properties, 3-polytope, neighborhood. 2010 Mathematics Subject Classification: 05C15.

\footnotetext{
${ }^{1}$ The work was funded by the Russian Science Foundation, grant 16-11-10054.
} 


\section{REFERENCES}

[1] V.A. Aksenov, O.V. Borodin and A.O. Ivanova, Weight of 3-paths in sparse plane graphs, Electron. J. Combin. 22 (2015) \#P3.28.

[2] K. Ando, S. Iwasaki and A. Kaneko, Every 3-connected planar graph has a connected subgraph with small degree sum, Annual Meeting of Mathematical Society of Japan (1993).

[3] O.V. Borodin, Solution of Kotzig's and Grünbaum's problems on the separability of a cycle in a planar graph, Mat. Zametki 46 (1989) 9-12, in Russian.

[4] O.V. Borodin, Joint generalization of the theorems of Lebesgue and Kotzig on the combinatorics of planar maps, Diskret. Mat. 3 (1991) 24-27, in Russian.

[5] O.V. Borodin, Joint extension of two Kotzig's theorems on 3-polytopes, Combinatorica 13 (1993) 121-125. doi:10.1007/BF01202794

[6] O.V. Borodin, Minimal vertex degree sum of a 3-path in plane maps, Discuss. Math. Graph Theory 17 (1997) 279-284.

doi:10.7151/dmgt.1055

[7] O.V. Borodin, Colorings of plane graphs: a survey, Discrete Math. 313 (2013) $517-539$. doi:10.1016/j.disc.2012.11.011

[8] O.V. Borodin and A.O. Ivanova, Describing $(d-2)$-stars at d-vertices, $d \leq 5$, in normal plane maps, Discrete Math. 313 (2013) 1700-1709. doi:10.1016/j.disc.2013.04.026

[9] O.V. Borodin and A.O. Ivanova, Describing 4-stars at 5-vertices in normal plane maps with minimum degree 5, Discrete Math. 313 (2013) 1710-1714. doi:10.1016/j.disc.2013.04.025

[10] O.V. Borodin, A.O. Ivanova and T.R. Jensen, 5-stars of low weight in normal plane maps with minimum degree 5, Discuss. Math. Graph Theory 34 (2014) 539-546. doi:10.7151/dmgt.1748

[11] O.V. Borodin and A.O. Ivanova, An analogue of Franklin's Theorem, Discrete Math. 339 (2016) 2553-2556. doi:10.1016/j.disc.2016.04.019

[12] O.V. Borodin and A.O. Ivanova, Light and low 5-stars in normal plane maps with minimum degree 5, Sibirsk. Mat. Zh. 57 (2016) 596-602, in Russian. doi:10.1134/S0037446616030071

[13] O.V. Borodin and D.R. Woodall, Short cycles of low weight in normal plane maps with minimum degree 5, Discuss. Math. Graph Theory 18 (1998) 159-164. doi:10.7151/dmgt.1071

[14] B. Ferencová and T. Madaras, Light graph in families of polyhedral graphs with prescribed minimum degree, face size, edge and dual edge weight, Discrete Math. 310 (2010) 1661-1675. doi:10.1016/j.disc.2009.11.027 
[15] Ph. Franklin, The four colour problem, Amer. J. Math. 44 (1922) 225-236. doi:10.2307/2370527

[16] J. Harant and S. Jendrol', On the existence of specific stars in planar graphs, Graphs Combin. 23 (2007) 529-543. doi:10.1007/s00373-007-0747-7

[17] A.O. Ivanova and D.V. Nikiforov, The structure of neighborhoods of 5-vertices in plane triangulation with minimum degree 5, Mat. Zam. YaSU 20(2) (2013) 66-78, in Russian.

[18] A.O. Ivanova and D.V. Nikiforov, Combinatorial structure of triangulated 3-polytopes with minimum degree 5, in: Proceedings of the Scientific Conference of students, graduate students, and young researchers. XVII and XVIII Lavrent'ev's reading, Yakutsk; Kirov: International Center for Research Project (2015) 22-27, in Russian.

[19] S. Jendrol', A structural property of convex 3-polytopes, Geom. Dedicata 68 (1997) 91-99. doi:10.1023/A:1004993723280

[20] S. Jendrol', Paths with restricted degrees of their vertices in planar graphs, Czechoslovak Math. J. 49 (1999) 481-490. doi:10.1023/A:1022411100562

[21] S. Jendrol' and M. Maceková, Describing short paths in plane graphs of girth at least 5, Discrete Math. 338 (2015) 149-158. doi:10.1016/j.disc.2014.09.014

[22] S. Jendrol', M. Maceková and R. Soták, Note on 3-paths in plane graphs of girth 4, Discrete Math. 338 (2015) 1643-1648. doi:10.1016/j.disc.2015.04.011

[23] S. Jendrol' and T. Madaras, On light subgraphs in plane graphs of minimal degree five, Discuss, Math. Graph Theory 16 (1996) 207-217. doi:10.7151/dmgt.1035

[24] S. Jendrol' and T. Madaras, Note on an existence of small degree vertices with at most one big degree neighbour in planar graphs, Tatra Mt. Math. Publ. 30 (2005) 149-153.

[25] S. Jendrol' and H.-J. Voss, Light subgraphs of graphs embedded in the plane-a survey, Discrete Math. 313 (2013) 406-421. doi:10.1016/j.disc.2012.11.007

[26] A. Kotzig, Contribution to the theory of Eulerian polyhedra, Mat. Eas. SAV (Math. Slovaca) 5 (1955) 101-113.

[27] A. Kotzig, From the theory of Eulerian polyhedra, Mat. Eas. SAV (Math. Slovaca) 13 (1963) 20-34, in Russian.

[28] H. Lebesgue, Quelques conséquences simples de la formule d'Euler, J. Math. Pures Appl. 19 (1940) 27-43. 
[29] D.V. Nikiforov, The structure of neighborhoods of 5-vertices in normal plane maps with minimum degree 5, Mat. Zam. YaSU, 23 (2016) 56-66, in Russian.

[30] O. Ore and M.D. Plummer, Cyclic coloration of plane graphs, in: Recent Progress in Combinatorics, W.T. Tutte, (Ed.), (Academic Press, New York, 1969) 287-293.

[31] E. Steinitz, Polyeder und Raumeinteilungen, Enzykl. Math. Wiss. (Geometrie), 3AB 12 (1922) 1-139.

[32] P. Wernicke, Über den kartographischen Vierfarbensatz, Math. Ann. 58 (1904) 413-426.

doi:10.1007/BF01444968

Received 12 July 2016

Revised 13 January 2017

Accepted 13 January 2017 